\title{
Overly-Optimism: Bilingual Effects on Cognitive Enhancement
}

\author{
Shuning $\mathrm{Li}^{1, *}$ \\ ${ }^{1}$ University of Bath, Bath, United Kingdom \\ "Corresponding author.Email: sl2792@bath.ac.uk
}

\begin{abstract}
The purpose of this review was to critically evaluate the previous literature on bilingual effects on executive function, in particular enhancement on attentional control. However, recent studies have shown inconsistent conclusions on the relationship between bilingualism and executive function. Such inconsistency could be attributed to the diversity of methodology, the complexity of bilingualism, and the lack of theoretical ground. Based on this review, the future direction would revise the theoretical framework to improve experimental design, and cautiously interpret and compare outcomes between studies. The ultimate aim is no longer to demonstrate whether bilingual advantages on executive function exist or not, but first to understand constitutions of bilingual experiences, then to investigate how different elements have potentially contributed to cognitive development over the lifespan. The significance of such investigations on bilingualism is not only practical for institutions to design effective foreign languages education for children within a normative trajectory, but also of importance to design and deliver effective interventions for the cognitive deficit populations.
\end{abstract}

Keywords: bilingualism, executive function, advances in executive function

\section{INTRODUCTION}

Under the globalization era, people who acquired more than one language, which refers to bilinguals, are advantageous in adapting to this rapid global interaction. And their advantages are not limited to greater communication opportunities, scientific review papers claimed that bilinguals are advanced in executive functions than monolinguals $[1,2]$. That is, bilinguals outperform than monolinguals in a variety of cognitive tasks. Moreover, neuroimaging studies have found functional and structural differences between monolinguals and bilinguals $[3,4]$. Specifically, bilinguals employed a different neural circuit when engaging in non-verbal tasks, that is left inferior frontal cortex and left striatum. This neural circuit underlies the language switching process. Combined with the advantages of bilinguals in task performance, this evidence infers that the bilingual experience leads to an enhancement in the fundamental cognitive function, which can be generalized to other tasks that involved cognitive control [3]. Similarly, the proficiency in the second language proficiency and the age of acquisition positively correlate to the density of grey matter in the left inferior parietal cortex. This further augments the standpoint that bilingualism is beneficial for cognitive development. Given such a valuable contribution, foreign language pieces of training have been widely adopted in the clinical population to tackle cognitive deterioration, such as aging [5].

However, recent reviews have critically evaluated these claims [6-7]. Firstly, the inconsistent methodology adopted in studies is disputed for leading to an overoptimistic verdict. This is due to that bilingualism is a common and complex domain, features of bilingualism are embedded in individual experiences which are difficult to precise capture [8]. Secondly, there is no scientific theory that explains the link between behavioural performances and bilingual experiences. This result to that our understanding remains on the claim of bilingualism benefit cognitive development. To progress into the next stage of applying bilingual effects on the population in need, the best would be to critically review current issues in capturing bilingualism and seeking for potential improvements for filling such gaps. Therefore, this review will take an integral stance to review methodology and potential moderators in previous literature, and exclusively focus on whether bilingualism would gain cognitive benefit. Firstly, this 
paper would outline the cognitive advantages bilinguals would receive compared to monolinguals mentioned in previous review papers. Secondly, it will critically evaluate methodological and theoretical issues that potentially explain the inconsistent stances between scholars. Finally, the current study would attempt to suggest improvements in future research.

\section{LITERATURE REVIEW}

\subsection{Benefits Of Bilingualism In Cognitive Control}

Over the last decades, the advantages and disadvantages of bilingualism have been well documented. According to early research, it was found that bilinguals excel in a variety of cognitive tasks [1]. The next section covers the advancement in cognitive function for bilinguals.

Given that bilinguals outperform monolinguals on a variety of cognitive tasks, early research inferred that bilingualism contributed to cognitive benefits. Bilingual children, for example, were found to be better than monolinguals at shifting their attention away from perceptual distracting information $[9,10]$. Older bilinguals have this advantage in attentional control [2, 11]. Bilinguals are found to have better working memory management, but only when the task is not semantically challenging [12]. This finding is in accord with recent research indicating that bilinguals are the disadvantage in lexical access, as it requires much more effort to select target languages [13]. It is also proposed that bilingual effects are generalisable to high-level cognitive functions such as cognitive flexibility, learning techniques, and abstract thinking skills in other studies [1, 14, 15]. Furthermore, research shows that bilinguals and monolinguals have functional and structural differences in cortical areas of the brain, which are linked to cognitive performance [4, 16, 17]. Longitudinal studies on second-language training have also revealed that bilingualism alters brain structure [3]. The bilingual experience of selective focus on target language could be one explanation for this cognitive enhancement $[1,18$, 19]. Bilinguals may have been inadvertently trained to control their attention as a result of frequent practices of resolving interference between languages. This improved attentional control then spreads to other higher-order cognitive skills that require executive control.

However, further research found that these cognitive advantages are subject to characteristics of the task and individual variance. Or as suggested by .., this bilingual effect in cognitive function does not exist. When the task requires a moderate level of attentional control, bilinguals lose their cognitive advantage over monolinguals [20, 21]. Furthermore, bilinguals , performance on cognitive tasks is moderated by individual differences, such as proficiency in the second language, age of language acquisition, and learning context [22-25]. Intriguingly, the cognitive advancement does not appear in bilingual adults, but the effect does reappear in older bilinguals [11]. And In contrast to previous research on neuroimaging findings, nonlinguistic experiences such as aerobic exercise can explain the functional and structural differences in bilinguals' brains [26]. Namely, although there is a clear difference in neural circuits between monolinguals and bilinguals, it is misleading to interpret this difference exclusively to the bilingual experience. When taken together, the contradictory findings suggest that bilinguals' cognitive advantage is conditional. It is unclear if multilingual experiences have led to improved attentional control, or whether this benefit is transferred from linguistic to non-linguistic areas. Furthermore, because of the complexities of bilingualism and individual differences, it is unclear which factors may have led to improved cognitive development. As a result, there is no solid evidence that bilingualism provides cognitive benefits because of their linguistic experiences.

\subsection{Methodological Constraints}

\subsubsection{Potential Misinterpretations On Correlational Design}

Existing bilingual literature can divide into three categories based on research design: correlational and experimental research. Correlational research investigates the correlation between variables, such as behavioral performance and neural circuity. It was found that monolinguals and bilinguals consistently recruited different neural circuits during language switching tasks [3, 27, 28]. Additionally, Garbin et al [29] discovered a link between bilinguals' behavioural measures and grey matter volume. However, it should be cautious of posthoc interpretations. First, in linguistic tasks, there are no causal relationships between neural correlates of attentional control. In other words, bilingual experiences may or may not cause the difference in neural circuitry recruited in the task. Second, neural circuit differences observed in language switching tasks may not apply to non-linguistic tasks. According to Rodrguez-Pujadas et al [28], although bilinguals' brain activation differed from monolinguals' brain activation, there was no significant difference in behavioral performance in non-linguistic control tasks. It is implausible to believe that bilingualism has shaped the brain in such a way that it has improved general executive function.

Experiments investigate the cause-and-effect relationships between variables, with the rationale that bilinguals engage in natural language training daily. When it comes to the relationship between bilingualism and executive control, however, it's unclear whether bilinguals' cognitive functioning improves because of their bilingual experience, or whether those with superior 
cognitive functioning are more likely to learn a foreign language [5]. Furthermore, because the independent variable remains constant, there may be known and unknown factors that influence the outcome. Even potential moderators are considered in the cross-sectional studies, it is unknown the measure of behavioral outcome primarily focuses on post-training performance only. That is, no further investigation is on which features of individual bilingual experiences have contributed to the outcome, such as the age of second language acquisition. As a result, while differences in cognitive performance indicate a possible causal relationship between bilingual experiences and general cognitive functioning, there is little more information about how this change occurs.

\subsubsection{Difficulties In Conceptualising And Measuring Bilingualism And Executive Functions}

Definition and measurement of bilingualism are the potential cause of inconsistencies [30]. Firstly, ideal bilinguals should be proficient in both languages. It is of importance to distinguish bilinguals from second language learners [31], as only when the proficiency of a second language reaches a certain level that the cognitive performance would be significantly distinct from monolinguals [32]. Studies adopt self-reports or objective measures on the level of bilingualism. Even though the former can give exclusive bilingual background information, it is prone to subjective bias. And assessing the level of bilingualism in young children is even more difficult. Furthermore, some studies have differentiated early bilinguals and late bilinguals depending on the age of acquisition of the second language [33], overlooking the qualitative difference in the language experiences is problematic. That is, although the second language is acquired later in life, the abundant exposure and dominant use of the second language may compensate for the deficiency in early language experiences. On the other hand, monolinguals' language acquisition is equally important. Limited studies have focused on how dialects have affected monolinguals' cognitive performance [34]. Furthermore, monolinguals may be inevitably influenced by cultural globalization. In this case, how the immersion of foreign content in media would impact on cognitive development deserves academic attention.

Another issue in the domain is the definition and measure of executive functions. Defined by Miyake et al [35], executive functions involve shifting, inhibiting information, and updating working memory. While without an agreement on unifying concepts and measures of executive functions, the better cognitive performance may be task-specific. Or the variety of cognitive tasks were measured as a latent common factor. Therefore, it is too early to conclude that bilingualism leads to an overall improvement in general executive functioning concerning methodological limitations.

\subsubsection{Lack of Theoretical Ground}

The most convincing model that accounts for the relation between bilingualism and cognitive functioning is the theory of joint activation. When equipped with two equally accessible language systems, bilinguals must focus on the target language system while suppressing the other. Fluent bilinguals are undoubtedly skilled at selectively attending to or switching between languages, and these language-specific advantages could be transferred to other tasks. This daily practice of resolving language conflicts control over language may serve to improve general executive control. However, this theory fails to explain the mechanism of transferring greater attentional control over languages to general executive control. In addition, given that speech-sign bilinguals do not experience cognitive conflicts over language, their performance on cognitive tasks supposed to be equally well as monolinguals. However, mixed findings suggest that there is a gap in interpreting task-specific performances and bilingual effects on general cognitive improvement [36, 37]. Taken together, it leaves very doubt on generalizing task-specific outcomes to an overall improvement in cognitive function and attributing this change to bilingual experiences alone.

This theory also renders little utility for understanding the relationship between language conflicts and cognitive benefits. Namely, how bilinguals receive cognitive benefits from managing conflicts. As the theory indicates, the type of bilingualism may affect potential cognitive benefits. Supported by Tao et al [38], who found English-Mandarin bilinguals displayed smaller but significant cognitive advantage relative to English-Spanish bilinguals. On the other hand, the difference in cognitive performance can be explained by the individual difference in cognitive ability. Instead of a one-directional causal relation between bilingualism and cognitive enhancement, it is also plausible that cognitively advantaged individuals are more likely to pick up more than one language. That is, fluency in the second language is the consequence of better cognitive functioning rather than the cause.

\section{LIMITATIONS AND FUTURE IMPLICATIONS}

This study has several limitations that require future studies. Firstly, this study mainly discusses the advantages of bilingualism, although there is evidence that bilingual vocabulary retrieval ability is deteriorating [38]. It is interesting to know how degrees and types of bilingualism would link to linguistic disadvantages on each language, and how individual differences emerge in dealing with such trade-off. Secondly, most studies 
mentioned in the review are healthy participants. Given that their bilingual experiences are diverse, it is hard to disentangle the impact of each component on cognitive performance. However, the clinical population is the alternative for working out how bilingual experience affects cognitive function. Thirdly, the focus of this review was limited to how bilingualism potentially contributed to cognitive function, it is more cogent to focus on the difference between bilinguals and secondlanguage learners, as well as the difference between bilinguals and multilingual. This helps to take a closer look at how bilingual (multilingual) experiences potentially lead to cognitive enhancement.

\section{CONCLUSION}

As recent studies have found null effects of bilingualism on cognitive function, this review has outlined potential reasons for these contradictory results. That is, without a theoretical ground, our interpretations on the link between bilingualism and cognitive effects can only be considered as a speculation rather than a firm conclusion, given that results were based on correlational researches. Although this review suggested that the cognitive benefits of bilingualism may be less appealing than it thought to be, it does not mean the application of foreign language interventions for the clinical population is of less significance. The investigations of clinical samples may promisingly render evidence of how bilingual experience contributes to cognitive function.

Furthering our understanding of the effect of secondlanguage acquisition in children's normative development is also crucial for educational institutions to deliver effective language lessons. Learning a second language becomes a necessity for a global citizen. Therefore, instead of arguing whether bilingualism has advantages over monolingualism for the typical population, the focus should shift towards what elements of bilingual experiences have benefited for cognitive development, and how individual differences potentially mediate such change.

To conclude, although the understanding of generalised cognitive benefits from bilingual experiences is less clear, this review still recommends devotion into the consequence of progress in second language acquisition for children within normative development, given that bilingualism is highly relevant in the current context.

\section{REFERENCES}

[1] O. O. Adesope, T. Lavin, T. Thompson, C. Ungerleider, A Systematic Review and MetaAnalysis of the Cognitive Correlates of Bilingualism. Review of Educational Research, 2010, 80(2), pp. 207-245. DOI: https://doi.org/10.3102/0034654310368803.
[2] E. Bialystok, F. I. M. Craik, G. Luk, Bilingualism: consequences for mind and brain. Trends in Cognitive Sciences, 2012, 16(4), pp. 240-250. DOI: https://doi.org/10.1016/j.tics.2012.03.001.

[3] G. Garbin, A.Sanjuan, C. Forn, J. C. Bustamante, A.Rodriguez-Pujadas, V. Belloch, M. Hernandez, A. Costa, C. Ávila, Bridging language and attention: Brain basis of the impact of bilingualism on cognitive control. NeuroImage, 2010, 53(4), pp. 1272-1278.

DOI: https://doi.org/10.1016/j.neuroimage.2010.05.078.

[4] A. Mechelli, J. T. Crinion, U. Noppeney, J. O’Doherty, J. Ashburner, R. S. Frackowiak, C. J. Price, Structural plasticity in the bilingual brain. Nature, 2004, 431(7010), pp. 757-757. DOI: https://doi.org/10.1038/431757a.

[5] M.Antoniou, G. M. Gunasekera, P. C. Wong, Foreign language training as cognitive therapy for age-related cognitive decline: a hypothesis for future research. Neuroscience \& Biobehavioral Reviews, 2013, 37(10), pp. 2689-2698.

[6] M. Lehtonen, A. Soveri, A. Laine, J. Järvenpää, A. de Bruin, J. Antfolk, Is bilingualism associated with enhanced executive functioning in adults? A meta-analytic review. Psychological Bulletin, 2018, 144(4), pp. 394-425. DOI: https://doi.org/10.1037/bul0000142.

[7] K. R., Paap, H. A. Johnson, O. Sawi, Bilingual advantages in executive functioning either do not exist or are restricted to very specific and undetermined circumstances. Cortex, 2015, 69, pp. 265-278.

[8] A. De Bruin, Not all bilinguals are the same: A call for more detailed assessments and descriptions of bilingual experiences. Behavioral Sciences, 2019, 9(3), pp. 33.

[9] E. Bialystok, Cognitive Complexity and Attentional Control in the Bilingual Mind. Child Development, 70(3), 1999, pp. 636-644. DOI: https://doi.org/10.1111/1467-8624.00046.

[10] E. Woumans, E. Ceuleers, L. Van der Linden, A. Szmalec, W. Duyck, Verbal and nonverbal cognitive control in bilinguals and interpreters. Journal of Experimental Psychology: Learning, Memory, and Cognition, 41(5), 2015, pp. 1579 .

[11] E. Bialystok, F. I. M. Craik, R. Klein, M. Viswanathan, Bilingualism, Aging, and Cognitive Control: Evidence From the Simon Task. Psychology and Aging, 19(2), 2004, pp. 290-303. DOI: https://doi.org/10.1037/0882-7974.19.2.290. 
[12] A. Ardila, Language representation and working memory with bilinguals. Journal of Communication Disorders, 36(3), 2003, pp. 233-240. DOI: https://doi.org/10.1016/s0021-9924(03)00022-4.

[13] C.Quinteros Baumgart, S. B. Billick, Positive Cognitive Effects of Bilingualism and Multilingualism on Cerebral Function: a Review. Psychiatric Quarterly, 89(2), 2017, pp. 273-283. DOI: https://doi.org/10.1007/s11126-017-9532-9.

[14] J. Cummins, The Influence of Bilingualism on Cognitive Growth: A Synthesis of Research Findings and Explanatory Hypotheses. Working Papers on Bilingualism, No. 9.1976.

[15] E. Le Pichon Vorstman, H. De Swart, V. Ceginskas, H. Van Den Bergh, Language learning experience in school context and metacognitive awareness of multilingual children. International Journal of Multilingualism, 6(3), 2009, pp. 258-280.

[16] A. Costa, N. Sebastián-Gallés, How does the bilingual experience sculpt the brain? Nature Reviews Neuroscience, 15(5), 2014, pp. 336-345. DOI: https://doi.org/10.1038/nrn3709.

[17] L. Li, J. Abutalebi, X. Zou,Yan, L. Liu, X. Feng, R. Wang, T. Guo, G. Ding, Bilingualism alters brain functional connectivity between "control" regions and "language" regions: Evidence from bimodal bilinguals. Neuropsychologia, 71, 2015, pp. 236247.

DOI: https://doi.org/10.1016/j.neuropsychologia.2015.04 .007 .

[18] E. Bialystok, The bilingual adaptation: How minds accommodate experience. Psychological Bulletin, 143(3), 2017, pp. 233-262. DOI: https://doi.org/10.1037/bul0000099.

[19] D. W. Green, Mental control of the bilingual lexicosemantic system. Bilingualism: Language and cognition, 1(2), 1998, pp. 67-81.

[20] M. M. Martin-Rhee, E. Bialystok, The development of two types of inhibitory control in monolingual and bilingual children. Bilingualism: language and cognition, 11(1), 2008, pp. 81-93.

[21] J. Morales, A. Calvo, E. Bialystok, Working memory development in monolingual and bilingual children. Journal of Experimental Child Psychology, 114(2), 2013, pp. 187-202. DOI: https://doi.org/10.1016/j.jecp.2012.09.002.

[22] J. Abutalebi, S. F. Cappa, D. Perani, The bilingual brain as revealed by functional neuroimaging. Bilingualism: Language and Cognition, 4(2), 2001, 179-190.

DOI: https://doi.org/10.1017/s136672890100027x.
[23] L. L. Kapa, J. Colombo, Attentional control in early and later bilingual children. Cognitive Development, 28(3), 2013, pp. 233-246. DOI: https://doi.org/10.1016/j.cogdev.2013.01.011.

[24] S. H. OOI, W. D. GOH, A. SORACE, T. H. BAK, From Bilingualism to Bilingualisms: Bilingual experience in Edinburgh and Singapore affects attentional control differently. Bilingualism: Language and Cognition, 21(4), 2018, pp. 867-879. DOI: https://doi.org/10.1017/s1366728918000020.

[25] C.-S. Tse, J. Altarriba, The relationship between language proficiency and attentional control in Cantonese-English bilingual children: evidence from Simon, Simon switching, and working memory tasks. Frontiers in Psychology, 5. 2014. DOI: https://doi.org/10.3389/fpsyg.2014.00954.

[26] V. Valian, Bilingualism and cognition. Bilingualism: Language and Cognition, 18(1), 2015, pp. 3-24.

[27] J. Abutalebi, P. A. Della Rosa, D. W. Green, M. Hernandez, P. Scifo, R. Keim, A. Costa, Bilingualism tunes the anterior cingulate cortex for conflict monitoring. Cerebral cortex, 22(9), 2012, pp. 2076-2086.

[28] A. Rodríguez-Pujadas, A. Sanjuán, N., VenturaCampos, P. Román, C. Martin, F, Barceló, C. Ávila, Bilinguals use language-control brain areas more than monolinguals to perform non-linguistic switching tasks. PLoS One, 8(9), 2013, pp. e73028.

[29] G. Garbin, A. Sanjuan, C. Forn, J. C. Bustamante, A. Rodriguez-Pujadas, V. Belloch, M. Hernandez, A. Costa, C. Ávila, Bridging language and attention: Brain basis of the impact of bilingualism on cognitive control. NeuroImage, 53(4), 2010, pp. 1272-1278.

DOI: https://doi.org/10.1016/j.neuroimage.2010.05.078.

[30] R. C. Weber, A. Johnson, C. A. Riccio, J. Liew, Balanced bilingualism and executive functioning in children. Bilingualism: Language and Cognition, 19(2), 2016, 425-431.

[31] C. Q. Baumgart, S. B. Billick, Positive cognitive effects of bilingualism and multilingualism on cerebral function: A review. Psychiatric Quarterly, 89(2), 2018, pp. 273-283.

[32] R. M. Diaz, Bilingual cognitive development: Addressing three gaps in current research. Child development, 1985, pp. 1376-1388.

[33] E. Bialystok, Cognitive effects of bilingualism: How linguistic experience leads to cognitive change. International journal of Bilingual education and bilingualism, 10(3), 2007, pp. 210-223. 
[34] V. Kempe, N. W. Kirk, P. J. Brooks, Revisiting theoretical and causal explanations for the bilingual advantage in executive functioning. Cortex, 73, 2015, pp. 342-344.

[35] A. Miyake, N. P. Friedman, M. J. Emerson, M. J. Witzki, A. Howerter, T. D. Wager, The unity and diversity of executive functions and their contributions to complex "frontal lobe" tasks: A latent variable analysis. Cognitive psychology, 41(1), 2000, pp. 49-100.

[36] E. Bialystok, F. I. M. Craik, Cognitive and Linguistic Processing in the Bilingual Mind. Current Directions in Psychological Science, 19(1), 2010, pp. 19-23. DOI: https://doi.org/10.1177/0963721409358571.

[37] E. Bialystok, Reshaping the mind: The benefits of bilingualism. Canadian Journal of Experimental Psychology/Revue Canadienne de Psychologie Expérimentale, 65(4), 2011, pp. 229-235. DOI: https://doi.org/10.1037/a0025406.

[38] L. Tao, M. Taft, T. H. Gollan, The Bilingual Switching Advantage: Sometimes Related to Bilingual Proficiency, Sometimes Not. Journal of the International Neuropsychological Society, 21(7),
2015,
pp.
531-544.
DOI: https://doi.org/10.1017/s1355617715000521. 